\title{
Usability Testing pada Sistem Peramalan Rentang Waktu Kerja Alumni ITB STIKOM Bali
}

\author{
M. Azman Maricar'1, Dian Pramana² \\ Fakultas Informatika dan Komputer \\ Institut Teknologi dan Bisnis (ITB) STIKOM Bali \\ Denpasar, Indonesia \\ e-mail: 12azman@stikom-bali.ac.id, 2dian@stikom-bali.ac.id \\ Diajukan: 15 Desember 2019; Direvisi: 17 Februari 2020; Diterima: 26 Februari 2020
}

\begin{abstract}
Abstrak
Dalam setiap membangun suatu sistem, sangat penting untuk memastikan bahwa sistem yang telah dibangun tersebut mampu digunakan dengan mudah oleh penggunanya. Untuk mengetahui seberapa mudah suatu sistem dapat digunakan, dapat dilakukan pengujian usability. Salah satu metode yang dapat digunakan dalam pengujian usability adalah System Usability Scale (SUS). Dalam penelitian ini dilakukan pengujian usability dengan metode tersebut terhadap sistem peramalan untuk meramalkan rentang waktu kerja alumni ITB STIKOM Bali. Rentang waktu kerja yang dimaksud adalah seberapa lama alumni ITB STIKOM Bali mendapatkan pekerjaan selepas mereka wisuda. Total responden yang digunakan adalah 105 responden. Dari pengujian tersebut didapatkan skor 67, kemudian skor tersebut diinterpretasikan dalam tiga jenis. Pertama interpretasi Acceptability Ranges, skor tersebut masuk ke range Marginal/Marginal-High. Kedua, interpretasi Grade Scale, skor tersebut masuk ke grade D. Dan ketiga, interpretasi Adjective Rating, skor tersebut masuk ke rating OK yang hampir mendekati Good. Skor 67 menandakan bahwa sistem yang telah dibangun masih harus diperbaiki agar mampu diterima dengan baik oleh penggunanya.
\end{abstract}

Kata kunci: Sistem, Pengujian usability, System Usability Scale (SUS).

\begin{abstract}
In every building a system, it is very important to ensure that the system that has been built is able to be used easily by its users. To find out how easily a system can be used, usability testing can be done. One method that can be used in usability testing is the System Usability Scale (SUS). In this study a usability test was conducted with this method for forecasting systems to predict the work span of graduate of ITB STIKOM Bali alumni. The working time span in question is how long ITB STIKOM Bali's graduate get a job after graduation. Total of respondents used were 105 respondents. The test obtained a score of 67, then the score was interpreted in three types. First interpretation of Acceptability Ranges, the score is in the Marginal / Marginal - High range. Second, Grade Scale interpretation, the score goes to grade D. And third, interpretation of Adjective Rating, the score goes to the OK rating which is almost close to Good. A score of 67 indicates that the system that has been built must still be improved in order to be able to be well received by its users.
\end{abstract}

Keywords: System, Usability testing, System Usability Scale (SUS).

\section{Pendahuluan}

Sistem peramalan rentang waktu kerja alumni ITB STIKOM Bali dibangun berdasarkan hasil penelitian yang telah melakukan perbandingan metode terhadap kasus tersebut. Metode yang dibandingkan adalah Nä̈ve Bayes dan K-Nearest Neighbor. Parameter yang digunakan untuk mendapatkan hasil rentang kerja tersebut adalah jenis kelamin, masa studi, dan IPK terakhir [1]. Manfaat yang didapatkan dari sistem tersebut adalah para alumni maupun mahasiswa yang masih aktif dapat memperkirakan rentang waktu yang dibutuhkan untuk mendapatkan pekerjaan. Hasil peramalan yang telah dilakukan, terekam di dalam sistem, yang tentunya dapat dipantau oleh institusi guna pengembangan agar menghasilkan mahasiswa yang berkualitas, tidak perlu menunggu waktu lama untuk mendapatkan pekerjaan, dan mampu bersaing. Hasil yang didapatkan dari penelitian tersebut adalah hasil akurasi dan MAPE Nä̈ve Bayes sedikit lebih baik dibandingkan dengan $K$-Nearest Neighbor khususnya $K$-Nearest Neighbor dengan nilai K $=9$. Naive Bayes

p-ISSN: 2089-1814; e-ISSN: 2460-3694; DOI: 10.30864/eksplora.v9i2.326 
mendapatkan hasil akurasi dan MAPE $83.83 \%$ dan $16.17 \%$, sedangkan K-Nearest Neighbor dengan nilai $\mathrm{K}=9$ mendapatkan hasil $82.34 \%$ dan $17.66 \%$ [1]. Rentang waktu yang dimaksud adalah seberapa lama alumni ITB STIKOM Bali mendapatkan pekerjaan selepas mereka wisuda [1].

Dalam setiap pembuatan suatu produk atau sistem / aplikasi, sangat penting untuk mendapatkan pengalaman pengguna yang baik. Mendapatkan pengalaman pengguna yang baik dapat menjadi sebuah indikator keberhasilan dari produk atau sistem/ aplikasi yang telah dibuat. Keberhasilan dalam membuat produk dapat dikatakan berhasil jika, produk yang dibuat mampu dengan mudah dipelajari, digunakan, serta memberikan kepuasan dan kenyamanan bagi pengguna. Salah satu hal yang perlu dilakukan untuk mengukur keberhasilan tersebut adalah dengan melakukan usability testing. Usability Testing perlu dilakukan sebelum produk yang kita buat benar-benar dirilis. Untuk melakukan pengujian tersebut pada penelitian ini, digunakan metode System Usability Scale (SUS), metode ini dianggap sebagai metode yang andal dan banyak digunakan dalam pengujian tersebut.

Beberapa penelitian sebelumnya telah menggunakan metode System Usability Scale (SUS) untuk usability testing. Penelitian yang membahas mengenai opinion mining terhadap kasus SARA melakukan usability testing terhadap sistem yang dibangun dan didapatkan hasil 85 yang artinya sistem tersebut dapat diterima oleh penggunanya [2]. Terdapat penelitian yang melakukan perbandingan skor SUS terhadap dua desain produk, desain yang pertama mendapatkan skor SUS sebesar 63.8 (marginal) dan desain kedua mendapatkan skor 82.2 (acceptable) [3]. Penelitian lainnya menggunakan metode SUS untuk menguji aplikasi PENTAS, didapatkan skor 46 yang artinya aplikasi tersebut tidak dapat diterima [4].

Hasil yang diharapkan pada usability testing terhadap sistem peramalan tersebut adalah mendapatkan hasil dengan skor terbaik yang menandakan bahwa sistem tersebut dapat digunakan dengan baik oleh penggunanya.

\section{Metode Penelitian}

Metode yang digunakan pada penelitian ini adalah System Usability Scale (SUS) yang merupakan salah satu metode dari Usability Testing. Metode tersebut memiliki 10 pertanyaan yang diujikan dan memiliki tata cara penilaian. Alur-alur yang dilakukan untuk mendapatkan hasil dari metode tersebut ditunjukkan pada Gambar 1.

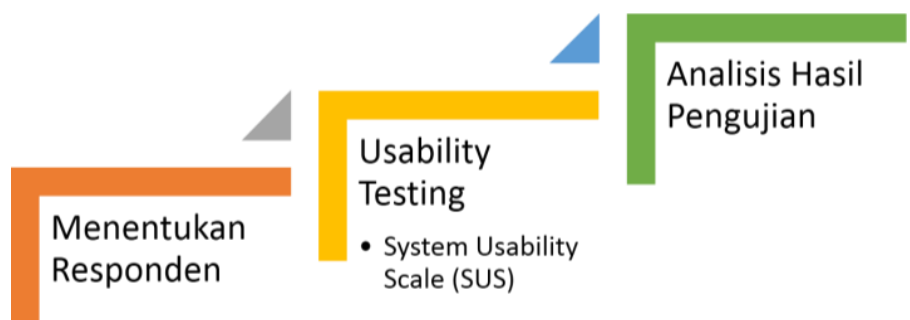

Gambar 1. Alur penelitian.

Langkah pertama yang dilakukan dalam penelitian ini adalah menentukan responden. Responden yang ditentukan adalah calon pengguna dari objek yang diuji. Langkah kedua, melakukan pengujian usability dengan metode System Usability Scale (SUS) terhadap objek yang diuji. Setelah melakukan pengujian, hasil pengujian tersebut diolah dan dibuatkan analisis agar dapat diketahui hal apa yang mempengaruhi hasil yang didapatkan serta lebih memudahkan untuk memahami hasil pengujian tersebut. Berikut Penjabaran dari masing-masing alur pada Gambar 1, yang dituangkan pada sub bab masing-masing.

\subsection{Menentukan Responden}

Target user dari sistem yang telah dibangun tersebut adalah mahasiswa aktif dari ITB STIKOM Bali. Target user tersebut sekaligus menjadi responden dalam penelitian ini. Penentuan mahasiswa aktif sebagai responden dikarenakan mahasiswa aktif tersebut adalah calon pengguna dari sistem yang telah dibangun.

\subsection{Usability Testing}

Pengertian usability menurut ISO 9241-11 adalah "Sejauh mana suatu produk dapat digunakan oleh pengguna tertentu untuk mencapai tujuan yang ditentukan dengan efektivitas, efisiensi dan kepuasan dalam konteks penggunaan tertentu" [2], [5]. Usability juga dapat berarti sesuatu yang mudah digunakan 
dengan baik, penggunaannya dapat digunakan untuk mengukur kualitas dari suatu produk yang berkaitan dengan mudah atau tidaknya dalam mempelajari maupun menggunakan suatu produk [6]-[10].

Salah satu metode atau alat untuk mengukur usability adalah System Usability Scale (SUS), yang merupakan metode yang cukup andal dan sering digunakan serta penggunaannya yang cukup mudah karena pertanyaan yang diuji serta tata cara penggunaannya telah tersedia [2]-[4], [6]-[8]. Skala penilaian SUS dari 1 -5 (dari sangat tidak setuju hingga sangat setuju) [2], [3]. Pertanyaan yang diujikan pada metode SUS ditunjukkan pada Tabel 1 [2], [3].

Tabel 1. Pertanyaan SUS.

\begin{tabular}{cl}
\hline No & \multicolumn{1}{c}{ Pertanyaan } \\
\hline 1 & Saya sepertinya akan sering menggunakan aplikasi ini. \\
\hline 2 & Saya melihat ada bagian fitur aplikasi ini yang cukup merepotkan, yang mestinya hal itu tidak perlu terjadi \\
\hline 3 & Saya rasa aplikasi ini mudah digunakan \\
\hline 4 & Saya sepertinya akan membutuhkan bantuan seorang teknisi agar bisa lancar menggunakan aplikasi ini. \\
\hline 5 & Saya rasa fitur-fitur aplikasi ini sudah terintegrasi dengan baik satu sama lain \\
\hline 6 & Saya menemukan terlalu banyak ketidak konsistenan dalam aplikasi ini \\
\hline 7 & Saya pikir orang-orang akan sangat cepat bisa menggunakan aplikasi ini \\
\hline 8 & Saya rasa aplikasi ini sangat sulit untuk digunakan \\
\hline 9 & Saya merasa mantap menggunakan aplikasi ini \\
\hline 10 & Saya mesti belajar banyak hal terlebih dahulu sebelum mulai menggunakan aplikasi ini \\
\hline
\end{tabular}

Tata cara penilaian SUS [2]-[4], [6]:

1. Setiap pertanyaan ganjil $(1,3,5,7,9)$, jawaban responden dikurangi satu.

2. Setiap pertanyaan genap $(2,4,6,8,10)$, lima dikurangi dengan jawaban responden.

3. Dari proses nomor 1 dan 2, akan menghasilkan skala sangat tidak setuju hingga sangat setuju $0-4$.

4. Jumlahkan seluruh jawaban dari responden yang sudah dilakukan proses 1 dan 2, kalikan 2.5 dan bagi dengan jumlah responden. Hal ini akan menghasilkan nilai dari $0-100$.

Dimana:

$$
U=\frac{\sum R X 2.5}{\mathrm{n}}
$$

$\mathrm{U}=$ Usability

$\sum \mathrm{R}=$ Total keseluruhan jawaban yang telah dilakukan proses 1 dan 2.

$\mathrm{N} \quad$ Jumlah Responden

5. Hasil yang diperoleh akan di pada poin 4, memiliki arti masing-masing. Arti skor yang diperoleh pada SUS ditunjukkan pada Tabel 2.

Tabel 2. Arti Skor SUS.

\begin{tabular}{cc}
\hline Skor SUS & Arti Skor \\
\hline $0-50,9$ & Not Acceptable \\
\hline $51-70,9$ & Marginal \\
\hline $71-100$ & Acceptable \\
\hline
\end{tabular}

Selain interpretasi hasil SUS berdasarkan Acceptability Ranges seperti Tabel 2, ada cara lain untuk menginterpretasikan hasil SUS dan cara-cara tersebut ditunjukkan pada Gambar 2 [4], [6], yaitu:

1. Grade Scale

Skor SUS yang dihasilkan dibagi menjadi lima grade yaitu A (90 - 100), B (80 - 90), C (70 - 80), D (60 - 70), dan F (Skor <60).

2. Adjective Rating

Menginterpretasikan skor SUS yang awalnya berupa numerik, menjadi kata sifat. Skala peringkat Adjective: Worst Imaginable, Awful, Poor, OK, Good, Excellence, dan Best Imaginable. 


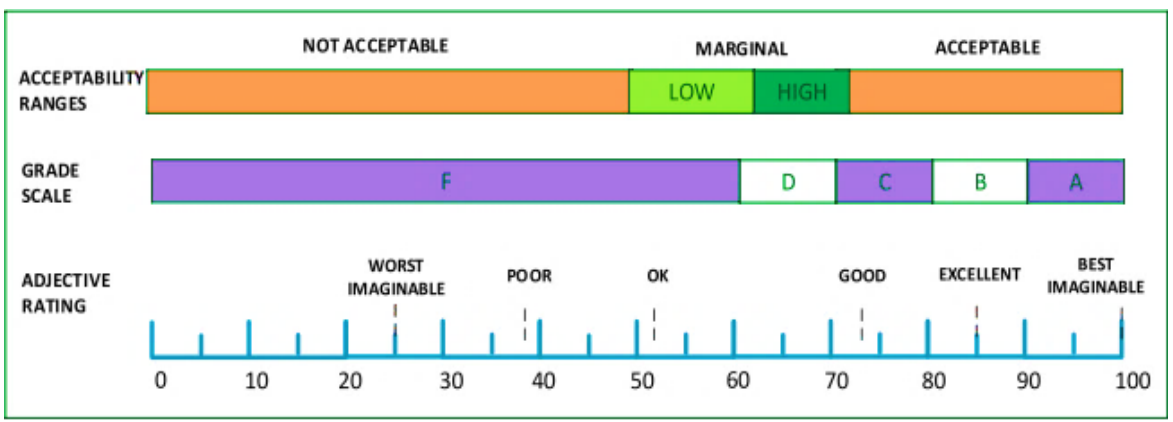

Gambar 2. Interpretasi Skor SUS Menurut Bangor dkk.

\subsection{Analisis Hasil Pengujian}

Setelah proses pengujian usability dilakukan dan didapatkan hasil, selanjutnya hasil dianalisis dengan merincikan setiap jawaban yang diberikan oleh responden guna mengetahui hal apa yang mempengaruhi sehingga didapatkan hasil atau skor SUS, serta mendapatkan kesimpulan yang lebih mudah untuk dipahami dari hasil pengujian yang dilakukan.

\section{Hasil dan Pembahasan}

Pada pengujian usability, digunakan teknik pengambilan data dengan kuesioner. Metode yang digunakan dalam pengujian usability adalah System Usability Scale (SUS), yang telah memiliki tata cara penilaian dan pertanyaan-pertanyaan (Tabel 1) yang akan diberikan ke responden. Responden dalam pengujian ini adalah Mahasiswa ITB STIKOM Bali dalam 3 kelas User Experience. Didapatkan 105 responden dari 122 mahasiswa yang ada.

Kuesioner disebar secara online dengan memanfaatkan fasilitas dari Google yaitu, Google Forms. Sebelum mengisi kuesioner, responden diberikan mockup flow dari sistem yang akan diuji. Setelah mempelajari mockup flow yang diberikan, responden mengisi jawaban pada setiap pernyataan-pernyataan yang diajukan secara online tersebut.

Untuk mendapatkan hasil dari usability testing, dilakukan tahap demi tahap sesuai dengan yang telah disediakan pada metode System Usability Scale (SUS). Hasil penjumlahan data yang telah dikonversi adalah 2811. Hasil tersebut dikalikan dengan 2.5, sehingga didapatkan hasil 7027.5. Langkah selanjutnya adalah membagi 7027.5 dengan jumlah responden yaitu 105, sehingga didapatkan hasil 66.93 yang jika dibulatkan menjadi 67. Skor 67 tersebut diinterpretasikan dalam tiga versi penilaian, yaitu:

1. Interpretasi dengan acceptability ranges:

a. Merujuk pada Tabel 2, maka skor 67 masuk ke dalam range Marginal.

b. Merujuk pada Gambar 2, maka skor 67 masuk ke dalam range Marginal - High.

2. Interpretasi dengan grade scale seperti Gambar 2, skor 67 masuk ke dalam grade scale D.

3. Interpretasi dengan adjective rating seperti Gambar 2, skor 67 masuk ke dalam rating $O K$ yang hampir mendekati Good.

Persentase hasil kuesioner untuk setiap jawaban dari masing-masing pertanyaan (Tabel 1), ditunjukkan pada Tabel 3 .

Tabel 3. Persentase hasil kuesioner.

\begin{tabular}{|c|c|c|c|c|c|}
\hline Pertanyaan No. & $\begin{array}{c}\text { Sangat Tidak } \\
\text { Setuju }\end{array}$ & Tidak Setuju & Netral & Setuju & Sangat Setuju \\
\hline 1 & $0 \%$ & $5 \%$ & $29 \%$ & $39 \%$ & $27 \%$ \\
\hline 2 & $15 \%$ & $22 \%$ & $40 \%$ & $14 \%$ & $9 \%$ \\
\hline 3 & $0 \%$ & $1 \%$ & $19 \%$ & $41 \%$ & $39 \%$ \\
\hline 4 & $20 \%$ & $27 \%$ & $24 \%$ & $16 \%$ & $12 \%$ \\
\hline 5 & $1 \%$ & $1 \%$ & $18 \%$ & $50 \%$ & $30 \%$ \\
\hline 6 & $19 \%$ & $31 \%$ & $31 \%$ & $11 \%$ & $8 \%$ \\
\hline 7 & $0 \%$ & $3 \%$ & $21 \%$ & $40 \%$ & $36 \%$ \\
\hline 8 & $26 \%$ & $41 \%$ & $22 \%$ & $5 \%$ & $6 \%$ \\
\hline 9 & $0 \%$ & $4 \%$ & $22 \%$ & $48 \%$ & $26 \%$ \\
\hline 10 & $13 \%$ & $27 \%$ & $18 \%$ & $26 \%$ & $16 \%$ \\
\hline
\end{tabular}

Dari Tabel 3, dapat dilihat bahwa hasil dari pengujian menyatakan bahwa sistem ini masih perlu dilakukan perbaikan agar mampu diterima dengan baik oleh pengguna. Rata-rata responden memberikan 
respons yang cukup positif, hal tersebut lebih banyak jika dibandingkan dengan responden yang memberikan respons negatif. Namun persentase responden yang memberikan respons netral juga tidak kalah besarnya, hal inilah yang menyebabkan SUS mendapatkan skor 67. Masalah-masalah yang terjadi dari hasil pengujian yang telah dilakukan adalah sebagai berikut:

1. Terdapat 5\% dari responden yang tidak setuju dengan pertanyaan 1, disebabkan oleh sistem ini digunakan hanya saat dibutuhkan, tidak digunakan secara rutin.

2. Terdapat $23 \%$ dari responden yang beranggapan bahwa terdapat bagian fitur dari sistem yang cukup merepotkan.

3. Terdapat $29 \%$ dari responden yang membutuhkan bantuan atau tutorial agar lebih lancar dalam menggunakan sistem.

4. Terdapat $19 \%$ dari responden yang menemukan ketidak konsistenan dari sistem.

5. Terdapat $11 \%$ dari responden beranggapan bahwa sistem sulit digunakan.

6. Terdapat $42 \%$ dari responden yang menganggap bahwa mereka perlu belajar banyak hal terlebih dahulu sebelum menggunakan sistem.

Hasil pengujian tersebut menunjukkan masalah-masalah yang dihadapi oleh responden saat mencoba sistem ini. Untuk mengatasi masalah tersebut perlu dilakukan perbaikan terhadap sistem. Adapun hal-hal yang perlu diperbaiki adalah penambahan fitur yang menarik agar sistem ini dapat digunakan secara rutin, perbaikan pada struktur menu dan penempatan komponen (button dan textbox) dibuat lebih berurutan, serta kombinasi warna untuk menambah daya tarik dari sistem tersebut, sehingga sistem terlihat lebih sederhana namun tetap terlihat menarik dan lebih mudah dan nyaman untuk digunakan. Dan perbaikan terakhir yang dapat dilakukan adalah dengan menambahkan tutorial penggunaan sistem untuk mengantisipasi jika ada bagian dari sistem yang belum dipahami oleh penggunanya.

\section{Kesimpulan}

Usability testing dalam penelitian ini dengan menggunakan metode System Usability Scale (SUS) didapatkan skor 67. Skor tersebut diinterpretasikan menjadi tiga macam interpretasi, yang pertama interpretasi acceptability ranges, di mana skor tersebut masuk ke dalam range Marginal/Marginal-High. Yang kedua interpretasi grade scale, di mana skor tersebut masuk ke dalam grade D. Dan yang ketiga interpretasi adjective rating, di mana skor tersebut masuk ke dalam rating $O K$ yang hampir mendekati Good. Rata-rata responden memberikan respons yang cukup positif, hal tersebut lebih banyak jika dibandingkan dengan responden yang memberikan respons negatif. Namun persentase responden yang memberikan respons netral juga tidak kalah besarnya, hal inilah yang menyebabkan SUS mendapatkan skor 67. Hasil tersebut menandakan bahwa keseluruhan responden menyatakan sistem ini masih perlu dilakukan perbaikan agar mampu diterima dengan baik oleh pengguna. Adapun hal-hal yang perlu diperbaiki adalah penambahan fitur yang menarik agar sistem ini dapat digunakan secara rutin, perbaikan pada struktur menu dan penempatan komponen (button dan textbox) dibuat lebih berurutan, serta kombinasi warna untuk menambah daya tarik dari sistem tersebut, sehingga sistem terlihat lebih sederhana namun tetap terlihat menarik dan lebih mudah dan nyaman untuk digunakan. Dan perbaikan terakhir yang dapat dilakukan adalah dengan menambahkan tutorial penggunaan sistem untuk mengantisipasi jika ada bagian dari sistem yang belum dipahami oleh penggunanya.

\section{Daftar Pustaka}

[1] M. A. Maricar and D. Pramana, "Perbandingan Akurasi Naï ve Bayes dan K-Nearest Neighbor pada Klasifikasi untuk Meramalkan Status Pekerjaan Alumni ITB STIKOM Bali,” J. Sist. DAN Inform., vol. 14, no. 1, pp. 16-22, 2019.

[2] M. A. Maricar, N. S. Kumara, and M. Sudarma, "Opinion Mining on Twitter Social Media to Classify Racism Using Combination of POS Tagging, Naive Bayes Classifier , and K-Nearest Neighbor," in International Conference on Smart-Green Technology in Electrical and Information System, 2019, no. October 2018, pp. 25-27.

[3] M. I. G. Ardiansyah, "Pengujian Usability User Interface Dan User Experience Aplikasi E-Reader Skripsi Berbasis Hypertext," JITTER ( J. Ilm. Tek. Inf. Ter., vol. II, no. 3, pp. 213-220, 2016.

[4] A. Saputra, "Penerapan Usability pada Aplikasi PENTAS Dengan Menggunakan Metode System Usability Scale ( SUS ) ( Usability Implementation in PENTAS Application Using the System Usability Scale ( SUS ) Method )," JTIM J. Teknol. Inf. dan Multimed., vol. 1, no. 3, pp. 206-212, 2019.

[5] L. D. Farida, "Pengukuran User Experience Dengan Pendekatan Usability [Kasus: Website Pariwisata Di Asia Tenggara]," in Seminar Nasional Teknologi Informasi dan Multimedia, 2016, pp. 6-7.

[6] Kharis, P. I. Santosa, and W. W. Winarno, "EVALUASI USABILITY PADA SISTEM INFORMASI 
PASAR KERJA MENGGUNAKAN SYSTEM USABLITY SCALE (SUS)," in Prosiding SNST ke10, 2019, pp. 240-245.

[7] A. W. Soejono, A. Setyanto, A. F. Sofyan, and W. Anova, "Evaluasi Usability Website UNRIYO Menggunakan S ystem Usability Scale ( Studi Kasus : Website UNRIYO )," J. Teknol. Inf., vol. XIII, no. 1, pp. 29-37, 2018.

[8] M. I. Farouqi, I. Aknuranda, and A. D. Herlambang, "Evaluasi Usability pada Aplikasi Go-Jek Dengan Menggunakan Metode Pengujian Usability," J. Pengemb. Teknol. Inf. dan Ilmu Komput., vol. 2, no. 10, pp. 3150-3156, 2018.

[9] E. Susilo, F. D. Wijaya, and R. Hartanto, "Perancangan dan Evaluasi User Interface Aplikasi Smart Grid Berbasis Mobile Application,” JNTETI, vol. 7, no. 2, pp. 150-157, 2018.

[10] M. S. Hartawan, "ANALISIS USER EXPERIENCE UNTUK USER INTERFACE PADA WEBSITE FORTIS . ID,” J. Teknol. Inf. ESIT, vol. XIV, no. 01, pp. 51-56, 2019. 